\title{
Influences of leakage currents on the transport properties and photoelectric effects in heterojunctions composed of colossal magnetoresistance manganites and $\mathrm{Nb}$-doped titanates
}

\author{
J. F. Wang, Z. P. Wu, and J. Gao ${ }^{a)}$ \\ Department of Physics, The University of Hong Kong, Pokfulam Road, Hong Kong
}

(Presented 1 November 2011; received 22 September 2011; accepted 7 December 2011; published online 12 March 2012)

\begin{abstract}
The effects of leakage currents were investigated for $\mathrm{Pr}_{0.7} \mathrm{Sr}_{0.3} \mathrm{MnO}_{3} / \mathrm{Nb}-\mathrm{SrTiO}_{3}$ heterojunctions. It was found that small amounts of leakage currents could cause pronounced detriment to the rectifying properties but had very limited impacts on the barrier heights determined from the forward currents. Significant open circuit voltages $\mathrm{V}_{\mathrm{OC}}$ were observed when the highly rectified junctions were illuminated by a visible light with a wavelength of $532 \mathrm{~nm}$. For the less rectified junctions, the leakage currents reduced $\mathrm{V}_{\mathrm{OC}}$ severely and resulted in an anomalous temperature dependence of $\mathrm{V}_{\mathrm{OC}}$. Theories for semiconductor contacts were employed in order to discuss these results. (C) 2012 American Institute of Physics. [doi:10.1063/1.3679413]
\end{abstract}

\section{INTRODUCTION}

Oxide heterostructures have garnered increasing interest in recent years. ${ }^{1-3}$ Distinct features are expected to emerge in heterostructures integrating complex oxides that already exhibit striking behaviors. In junctions formed with colossal magnetoresistance (CMR) manganites and $\mathrm{Nb}$ doped strontium titanates, interesting phenomena such as photoelectric effects, magnetoresistance, and magnetocapacitance have been reported. $^{4-14}$ However, these characteristics have not been well understood. The detailed modeling of these junctions is hampered by the strong correlations between electrons in CMR manganites. One route for analyzing these junctions is to use theories developed for conventional semiconductor contacts. ${ }^{6,8,11,15}$ This method is incomplete but instructive. Complexity also arises from non-ideal factors (e.g., leakage currents due to defects such as pinholes) in these heterostructures. ${ }^{12}$ In spite of their importance, the influence of extrinsic effects such as leakage currents has been rarely addressed. In this paper, we study the impacts of leakage currents in $\operatorname{Pr}_{0.7} \mathrm{Sr}_{0.3} \mathrm{MnO}_{3}$ (PSMO)/0.05 wt. \% $\mathrm{Nb}$ doped $\mathrm{SrTiO}_{3}$ (Nb-STO) heterojunctions. This is achieved by comparing transport behaviors and photoelectric responses in various junctions. As the properties of manganites can be affected significantly by deposition parameters, it is not good to analyze junctions on different substrates. Furthermore, the smaller the junction area, the larger the opportunity to get a junction with fewer imperfections. ${ }^{10}$ For these reasons, heterojunctions of a small size on the same substrates were investigated. The influence of leakage currents on the transport properties differs significantly under different bias voltages. Significant open circuit voltages were observed in the highly rectified junctions. The open circuit voltage is found to be sensitive to imperfections.

\footnotetext{
a) Author to whom correspondence should be addressed. Electronic mail: jugao@hku.hk.
}

\section{EXPERIMENTAL}

Epitaxial PSMO films $(100 \mathrm{~nm})$ on $(001)$ oriented NbSTO and $\mathrm{SrTiO}_{3}$ (STO) substrates were fabricated via pulsed laser ablation. ${ }^{16}$ The crystalline quality of grown films was examined by means of $\mathrm{x}$-ray diffraction (XRD). No secondary phase could be found in the XRD spectra. The small-area junctions were formed by using photolithography to define the pattern $\left[(\sim 400 \times 400) \mu \mathrm{m}^{2}\right.$ blocks] and hydrogen chloride $(\mathrm{HCl})$-potassium iodide $(\mathrm{KI})$ etchant to remove the uncovered PSMO. Silver was evaporated onto PSMO and $\mathrm{Nb}-\mathrm{STO}$ as electrodes. Given that the current-voltage curves for $\mathrm{Ag} / \mathrm{PSMO}$ (on STO)/Ag and $\mathrm{Ag} / \mathrm{Nb}-\mathrm{STO} / \mathrm{Ag}$ were linear, the $\mathrm{Ag} / \mathrm{PSMO}$ and $\mathrm{Ag} / \mathrm{Nb}-\mathrm{STO}$ contacts should be Ohmic. All current-voltage curves were recorded with the two-point contacts method. To measure the photoelectric responses, a semiconductor laser diode (wavelength $=532 \mathrm{~nm}$ ) was used as the light source.

\section{RESULTS AND DISCUSSIONS}

Figure 1(a) shows the current-voltage ( $\mathrm{J}$ versus V) relations for two representative PSMO/Nb-STO junctions on the same substrates. Here, the positive direction is defined as a current flow from PSMO to Nb-STO. Both junctions exhibit clear current rectification $\left[|\mathrm{J}(1 \mathrm{~V})| /|\mathrm{J}(-1 \mathrm{~V})|>10^{5}\right]$. The most obvious discrepancy between these two junctions is the characteristic under reverse bias. The backward currents in one junction start to increase steeply at larger voltages, i.e., $\sim-9 \mathrm{~V}$. This junction is called junction $H$. In the other junction, denoted as junction L, this occurs at much lower voltages, i.e., $\sim-2 \mathrm{~V}$. At first glance, the forward J versus $\mathrm{V}$ curves for these two junctions are similar. One difference lies in the biases, which are smaller than the threshold voltages where the current begins to rush [see the inset of Fig. 1(a)]. These features indicate that for junction $\mathrm{L}$ there are leakage currents. ${ }^{12}$

For either junction, the forward $\log \mathrm{J}$ versus $\mathrm{V}$ curves are clearly linear as $\mathrm{J}$ changes from $\sim 10^{-6} \mathrm{~A} / \mathrm{cm}^{2}$ to $\sim 10^{-3}$ $\mathrm{A} / \mathrm{cm}^{2}$. This reminds us of the current transports in $\mathrm{p}-\mathrm{n}$ and 


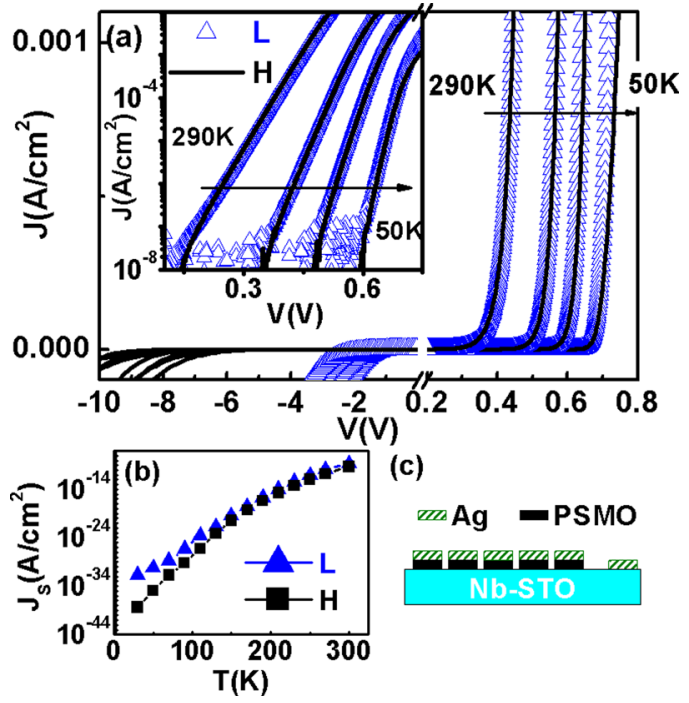

FIG. 1. (Color online) (a) J vs V plots at 290, 210, 130, and $50 \mathrm{~K}$. (b) $\mathrm{J}_{\mathrm{S}}$ as a function of temperature. (c) Schematic view of the junctions.

Schottky junctions, in which the forward current-voltage relations can be approximately expressed as $\mathrm{J}=\mathrm{J}_{\mathrm{S}} \exp$ $\left(\mathrm{qV} / \mathrm{nk}_{\mathrm{B}} \mathrm{T}\right)$ when $\mathrm{qV} \gg 3 \mathrm{k}_{\mathrm{B}} \mathrm{T}$. ${ }^{17}$ Here $\mathrm{J}_{\mathrm{S}}, \mathrm{n}$, and $\mathrm{k}_{\mathrm{B}}$ are the saturation current density, ideality factor, and Boltzmann constant, respectively. In order to gain further insight, we use such models to analyze our junctions. The first step is to fit $\ln$ $\mathrm{J}$ versus $\mathrm{V}$ plots with straight lines. The intercept and slope of the fitted curves give $\ln \mathrm{J}_{\mathrm{S}}$ and $\mathrm{q} / \mathrm{nk}_{\mathrm{B}} \mathrm{T}$, respectively. The temperature dependence of $\mathrm{J}_{\mathrm{S}}$ is displayed in Fig. 1(b). Junction $\mathrm{L}$ has a slightly larger $\mathrm{J}_{\mathrm{S}}$. As a consequence, for junction $\mathrm{L}$, the barrier heights $\mathrm{q} \Phi_{\mathrm{B}}$ deduced with the thermionic emission current formula $\mathrm{JS}=\mathrm{A}^{*} \mathrm{~T}^{2} \exp \left(\mathrm{q} \phi_{\mathrm{B}} / \mathrm{k}_{\mathrm{B}} \mathrm{T}\right),{ }^{17}$ where $\mathrm{A}^{*}$ is the effective Richardson constant, are a little bit lower [see Fig. 2(b)]. This means that a small amount of leakage currents lead to a slight underestimation of $\mathrm{q}_{\mathrm{B}}$. The barrier height can also be deduced from the slope of the $\ln \left(\mathrm{J}_{\mathrm{S}} / T^{\alpha}\right)$ versus $1 /$ $\mathrm{T}$ plot $(\alpha=1,2){ }^{8}$ For both junctions, the slope of the

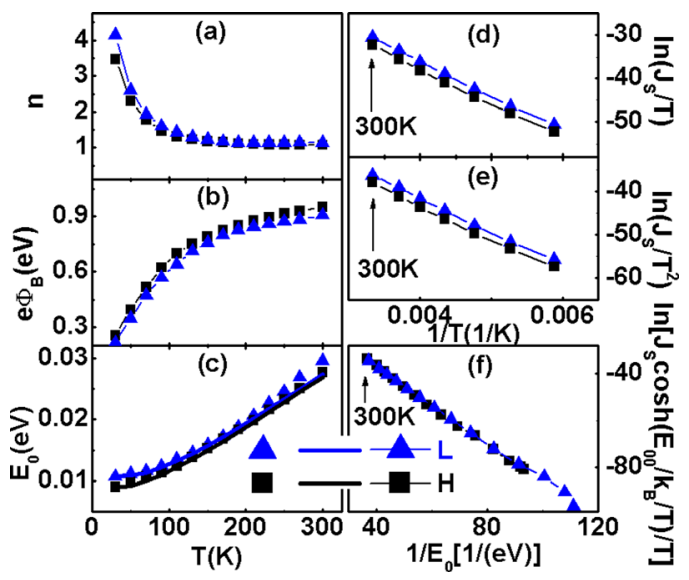

FIG. 2. (Color online) Comparison of parameters for junctions $\mathrm{H}$ and L: (a) ideality factor $\mathrm{n}$, (b) barrier height $\mathrm{e} \Phi_{\mathrm{B}}$ [deduced with $\mathrm{J}_{\mathrm{S}}=\mathrm{A}^{*} \mathrm{~T}^{2} \exp$ $\left(-\mathrm{q} \Phi_{\mathrm{B}} / \mathrm{k}_{\mathrm{B}} \mathrm{T}\right), \mathrm{A}^{*}=156 \mathrm{~A} / \mathrm{cm}^{2} / \mathrm{K}^{2}$ ], (c) $\mathrm{E}_{0}$ [deduced with $E_{0}(\mathrm{~T})=E_{00}$ coth $\left(E_{00} / k_{B} T\right)$ (lines, $\mathrm{E}_{00}=\mathrm{q} /$ slope of $\operatorname{lnJ}$ vs $\mathrm{V}$ plot at $30 \mathrm{~K}$ ) and $\mathrm{E}_{0}(\mathrm{~T})=$ $\mathrm{q} /$ slope of $\operatorname{lnJ}$ vs $\mathrm{V}$ plot at T (squares and triangles)] as a function of temperature; (d) $\ln \mathrm{J}_{\mathrm{S}} / \mathrm{T}$ vs $1 / \mathrm{T}$ plots; (e) $\ln \mathrm{J}_{\mathrm{S}} / \mathrm{T}^{2}$ vs $1 / \mathrm{T}$ plots; (f) $\ln \left[\mathrm{J}_{\mathrm{S}} \cosh \left(\mathrm{E}_{00} / \mathrm{k}_{\mathrm{B}} \mathrm{T}\right) / \mathrm{T}\right]$ vs $1 / \mathrm{E}_{0} \quad\left(\mathrm{E}_{00}=\mathrm{q} /\right.$ slope of $\ln \mathrm{J}$ vs $\mathrm{V}$ plot at $30 \mathrm{~K}$, $\mathrm{E}_{0}=\mathrm{q} /$ slope of $\operatorname{lnJ}$ vs $\mathrm{V}$ plot at $\mathrm{T}$ ) characteristics. $\ln \left(\mathrm{J}_{\mathrm{S}} / T\right)$ versus $1 / \mathrm{T}$ plot [Fig. 2(d)] gives a barrier height of $0.68 \mathrm{eV}$, and the slope of the $\ln \left(\mathrm{J}_{\mathrm{S}} / T^{2}\right)$ versus $1 / T$ plot [Fig. $2(\mathrm{e})]$ yields a barrier height of $0.66 \mathrm{eV}$. As can be seen from Fig. 2(a), the leakage currents caused a slight overestimation of $n$. For a $\mathrm{p}-\mathrm{n}$ junction with a purely diffusion process or a Schottky junction with a purely thermal emission process, $\mathrm{n}$ is $1 .^{17}$ At room temperature, ideality factors are $\sim 1.1$, implying that the thermal or diffusion process dominates. The deviation from unity could be due to the involvement of other transport processes, e.g., recombination and tunneling, or junction inhomogeneity. ${ }^{17}$ When the temperature decreases, $n$ rises monotonously, suggesting increasing components of other transport processes. Because of the relatively high carrier densities in PSMO $\left(\sim 10^{21} \mathrm{~cm}^{-3}\right)$ and Nb-STO $\left(\sim 10^{19} \mathrm{~cm}^{-3}\right)$, it is possible that the low-temperature carrier transport is mainly a direct tunneling process $\left[\mathrm{J}=\mathrm{J}_{\mathrm{S}} \exp \left(\mathrm{qV} / \mathrm{E}_{00}\right), \quad \mathrm{E}_{00}=(\mathrm{qh} / 4 \pi) \quad \sqrt{\mathrm{N}_{\mathrm{d}} / \mathrm{m} * \varepsilon_{\mathrm{S}}}\right] .11,14,17$ Here, $\mathrm{h}$ is Planck's constant, $\mathrm{N}_{\mathrm{d}}$ is the donor concentration, $\mathrm{m}^{*}$ is the effective mass, and $\varepsilon_{\mathrm{S}}$ is the permittivity of the semiconductor. Then, the thermally assisted tunneling $\left[\mathrm{J}=\mathrm{J}_{\mathrm{S}} \exp \left(\mathrm{qV} / \mathrm{E}_{0}\right), E_{0}=E_{00} \operatorname{coth}\left(E_{00} / k_{B} T\right)\right]$ should dominate at intermediate temperatures. ${ }^{11,14,17}$ As shown in Fig. 2(c), for a given $\mathrm{T}$, the values of $E_{00} \operatorname{coth}\left(E_{00} / k_{B} T\right)$ $\left[(\mathrm{q} /\right.$ slope of $\ln \mathrm{J}$ vs $\mathrm{V}$ plot at $30 \mathrm{~K})$ is used as $\left.\mathrm{E}_{00}\right]$ and $\mathrm{q} /$ (slope of $\operatorname{lnJ}$ vs $\mathrm{V}$ plot at $\mathrm{T}$ ) are close, implying that this model is applicable. ${ }^{11}$ The estimated $\mathrm{q} \Phi_{\mathrm{B}}$ from the slope of the $\ln \left[\mathrm{J}_{\mathrm{S}} \cosh \left(\mathrm{E}_{00} / \mathrm{k}_{\mathrm{B}} \mathrm{T}\right) / \mathrm{T}\right]$ versus $1 / \mathrm{E}_{0}$ plot [Fig. 2(f)] is $0.85 \mathrm{eV}$ and $0.82 \mathrm{eV}$ for junctions $\mathrm{H}$ and $\mathrm{L}$, respectively.

It is very interesting to note that despite the clear differences in rectifying properties, the deduced barrier heights for junctions $\mathrm{H}$ and $\mathrm{L}$ are very close. This should be understandable if one considers the magnitudes of currents under different bias voltages in a "perfect" junction. When the forward biases reach the threshold values, the currents start to rush. Small amounts of leakage currents should have a very limited impact. Because the barrier heights are determined using the slopes and intercepts of $\ln \mathrm{J}-\mathrm{V}$ curves in this region, the estimated barrier heights would not be influenced significantly. In contrast, under backward or small forward bias
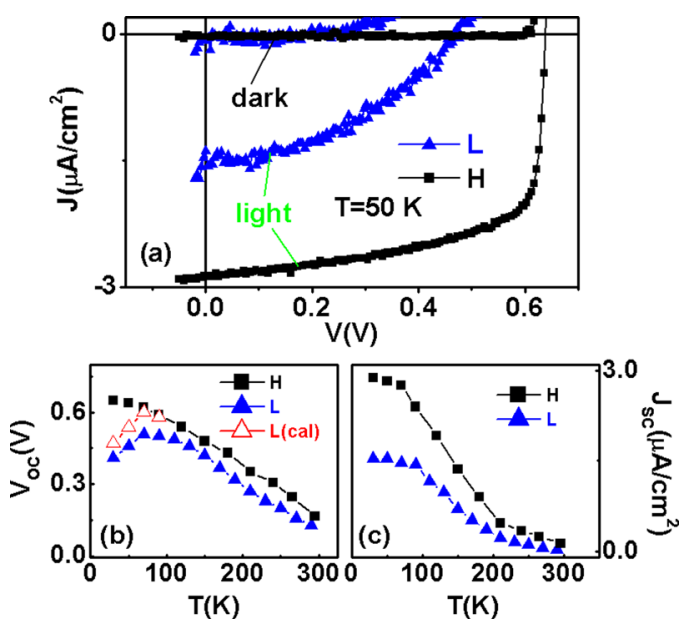

FIG. 3. (Color online) Comparison of photo responses: (a) J vs V plots with and without light $\left(\lambda=532 \mathrm{~nm}, \mathrm{P}=2 \mathrm{~mW} / \mathrm{mm}^{2}\right)$ at $50 \mathrm{~K}$; temperature dependences of $\mathrm{V}_{\mathrm{OC}}(\mathrm{b})$ and $\mathrm{J}_{\mathrm{sc}}(\mathrm{c})$. In (b), $\mathrm{V}_{\mathrm{OC}}$ calculated from dark J vs V curves [junction L, Fig. 4(b)] is also shown (pink open triangles). 

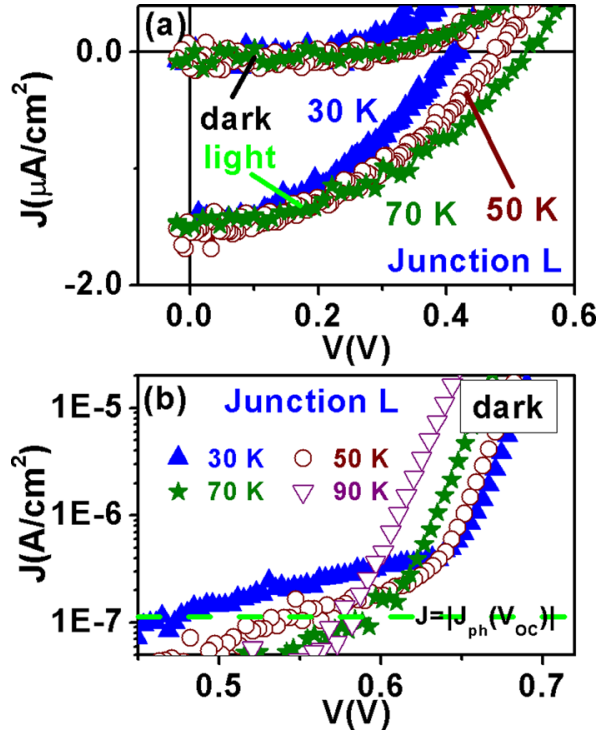

FIG. 4. (Color online) (a) J vs V curves with and without light $(\lambda=532 \mathrm{~nm}$, $\mathrm{P}=2 \mathrm{~mW} / \mathrm{mm}^{2}$ ) at 30,50 , and $70 \mathrm{~K}$ for junction $\mathrm{L}$; (b) forward $\mathrm{J}$ (on the log scale) vs $\mathrm{V}$ relations (without light) at $30,50,70$, and $90 \mathrm{~K}$ for junction $\mathrm{L}$.

voltages, the intrinsic currents are very small, and therefore they should be easily affected. The appearance of leakage currents suggests the existence of interfacial defects, such as pinholes and dislocations, which might be the channels for charge leaking. ${ }^{12}$ These defects might also facilitate the electric breakdown. ${ }^{17}$ As a consequence, for junction $\mathrm{L}$, the backward current rushes dramatically under relatively low bias voltages.

Illumination by visible light would excite excess carriers. It is of interest to see how these two junctions response to photo-excited carriers. As depicted in Fig. 3(a), with light illumination, both junctions show clear changes. The evolutions of the open circuit voltage $\mathrm{V}_{\mathrm{OC}}$ and the short circuit current density $\mathrm{J}_{\mathrm{SC}}$ are displayed in Figs. 3(b) and 3(c), respectively. For junction $\mathrm{H}, \mathrm{V}_{\mathrm{OC}}$ and $\mathrm{J}_{\mathrm{SC}}$ increase with a decrease in the temperature. The values of $\mathrm{V}_{\mathrm{OC}}$ are close to those observed in $\mathrm{Nd}_{0.7} \mathrm{Sr}_{0.3} \mathrm{MnO}_{3} / \mathrm{Nb}-\mathrm{STO} .{ }^{14} \mathrm{~V}_{\mathrm{OC}}$ and $\mathrm{J}_{\mathrm{SC}}$ in junction $\mathrm{L}$ are smaller. In our experiments, it is a general trend that the junction with less rectifying property has smaller values of $\mathrm{V}_{\mathrm{OC}}$ and $\mathrm{J}_{\mathrm{SC}}$. Such differences should be due to leakage currents. The leakage current causes an equivalent parasitic resistance. ${ }^{17}$ As a consequence, the effective output voltage and current are lowered. The peculiar feature for junction $\mathrm{L}$ is that when the temperature decreases from $70 \mathrm{~K}$ to $30 \mathrm{~K}, \mathrm{~V}_{\mathrm{OC}}$ also decreases, as displayed in Fig. 3(b) and Fig. 4(a). The measurements were repeated several times in order to make sure that such an anomalous temperature dependence of $\mathrm{V}_{\mathrm{OC}}$ is not an artifact. As it was not observed in junction $\mathrm{H}$, it should also be caused by leakage currents. Very roughly, $\mathrm{V}_{\mathrm{OC}}$ might be estimated from interception points of the "dark" $\mathrm{J}$ versus $\mathrm{V}$ curve and $\mathrm{J}=\left|\mathrm{J}_{\mathrm{ph}}\left(\mathrm{V}_{\mathrm{OC}}\right)\right|$ [Fig. 4(b)], where $\mathrm{J}_{\mathrm{ph}}\left(\mathrm{V}_{\mathrm{OC}}\right)$ is the photocurrent at $\mathrm{V}=\mathrm{V}_{\mathrm{OC}}$. If we assume $\left|\mathrm{J}_{\mathrm{ph}}\left(\mathrm{V}_{\mathrm{OC}}\right)\right|$ is $100 \mathrm{nA} / \mathrm{cm}^{2}$ (at $30,50,70$, and $90 \mathrm{~K}$ ), the calculation would qualitatively reproduce the temperature dependence of $\mathrm{V}_{\mathrm{OC}}$ in this temperature range [see Fig. 3 (b) and Fig. 4(b)].

\section{CONCLUSIONS}

The effects of leakage currents were studied for PSMO/ $\mathrm{Nb}$-STO heterojunctions by comparing the current transport (both with and without light illumination) for two smallsized junctions on the same substrates. Small amounts of leakage currents could severely increase the backward currents but would not influence the barrier heights extracted from the forward currents. Significant open circuit voltages $\mathrm{V}_{\mathrm{OC}}$ were observed in junctions with high rectification properties. As a result of leakage currents, in the less rectified junctions, the magnitudes of $\mathrm{V}_{\mathrm{OC}}$ were much smaller and the temperature dependence of $\mathrm{V}_{\mathrm{OC}}$ was anomalous at low temperatures. The sensitivity of $\mathrm{V}_{\mathrm{OC}}$ makes it useful in identifying non-ideal factors in manganite-titanate junctions.

\section{ACKNOWLEDGMENTS}

This work is supported by a grant from the Research Grant Council of Hong Kong (Project No. HKU 702409 P) and Seed Funding from the University of Hong Kong.

${ }^{1}$ J. Mannhart and D. G. Schlom, Science 327, 1607 (2010).

${ }^{2}$ H. Takagi and H. Y. Hwang, Science 327, 1601 (2010).

${ }^{3}$ P. Zubko, S. Gariglio, M. Gabay, P. Ghosez, and J.-M. Triscone, Annual Review of Condensed Matter Physics 2, 141 (2011).

${ }^{4}$ M. Sugiura, K. Uragou, M. Noda, M. Tachiki, and T. Kobayashi, Jpn. J. Appl. Phys. 38, 2675 (1999).

${ }^{5}$ H. Tanaka, J. Zhang, and T. Kawai, Phys. Rev. Lett. 88, 027204 (2001).

${ }^{6}$ F. M. Postma, R. Ramaneti, T. Banerjee, H. Gokcan, E. Haq, D. H. A. Blank, R. Jansen, and J. C. Lodder, J. Appl. Phys. 95, 7324 (2004).

${ }^{7}$ N. Nakagawa, M. Asai, Y. Mukunoki, T. Susaki, and H. Y. Hwang, Appl. Phys. Lett. 86, 082504 (2005).

${ }^{8}$ A. Sawa, T. Fujii, M. Kawasaki, and Y. Tokura, Appl. Phys. Lett. 86, 112508 (2005).

${ }^{9}$ Z. Luo and J. Gao, J. Appl. Phys. 100, 056104 (2006).

${ }^{10}$ A. Ruotolo, C. Y. Lam, W. F. Cheng, K. H. Wong, and C. W. Leung, Phys. Rev. B 76, 075122 (2007).

${ }^{11}$ T. Susaki, N. Nakagawa, and H. Y. Hwang, Phys. Rev. B 75, 104409 (2007).

${ }^{12}$ D. J. Wang, J. R. Sun, Y. W. Xie, W. M. Lu, S. Liang, T. Y. Zhao, and B. G. Shen, Appl. Phys. Lett. 91, 062503 (2007).

${ }^{13}$ Z. Luo, J. Gao, A. B. Djurisic, C. T. Yip, and G. B. Zhang, Appl. Phys. Lett. 92, 182501 (2008).

${ }^{14}$ J. F. Wang and J. Gao, J. Appl. Phys. 109, 07 d708 (2011).

${ }^{15}$ P. Han, K. J. Jin, H. B. Lu, Q. L. Zhou, Y. L. Zhou, and G. Z. Yang, Appl. Phys. Lett. 91, 182102 (2007).

${ }^{16}$ J. Gao, S. Y. Dai, and T. K. Li, Phys. Rev. B 67, 153403 (2003).

${ }^{17}$ S. M. Sze and K. K. Ng, Physics of Semiconductor Devices, 3rd ed. (John Wiley \& Sons, Inc., Hoboken, NJ, 2007). 